\title{
Lowering cholesterol concentrations and mortality: a quantitative review of primary prevention trials
}

\author{
Matthew F|Muldoon, Stephen B/Manuck, Karen A Matthews
}

\section{Abstract}

Objective-To determine the effects of lowering cholesterol concentrations on total and cause specific mortality in randomised primary prevention trials.

Design-Qualitative (meta-analytic) evaluation of total mortality from coronary heart disease, cancer, and causes not related to illness in six primary prevention trials of cholesterol reduction (mean duration of treatment 4.8 years).

Patients-24847 Male participants; mean age $47 \cdot 5$ years.

Main outcome measures-Total and cause specific mortalities.

Results-Follow up periods totalled 119000 person years, during which 1147 deaths occurred. Mortality from coronary heart disease tended to be lower in men receiving interventions to reduce cholesterol concentrations compared with mortality in control subjects $(p=0.06)$, although total mortality was not affected by treatment. No consistent relation was found between reduction of cholesterol concentrations and mortality from cancer, but there was a significant increase in deaths not related to illness (deaths from accidents, suicide, or violence) in groups receiving treatment to lower cholesterol concentrations relative to controls $(p=0.004)$. When drug trials were analysed separately the treatment was found to reduce mortality from coronary heart disease significantly $(p=0.04)$.

Conclusions - The association between reduction of cholesterol concentrations and deaths not related to illness warrants further investigation. Additionally, the failure of cholesterol lowering to affect overall survival justifies a more cautious appraisal of the probable benefits of reducing cholesterol concentrations in the general population.

University of Pittsburgh, Pittsburgh, Pennsylvania, United States

Matthew F Muldoon, MD, assistant professor, department of medicine

Stephen B Manuck, PHD, professor, department of psychology

Karen A Matthews, PHD, professor, department of psychiatry

Correspondence and requests for reprints to: Dr Matthew Muldoon, 506 Old Engineering Hall, University of Pittsburgh, Pittsburgh, PA 15260, United States.

BrMed f 1990;301:309-14 of atherosclerosis and that reduction of the serum cholesterol concentration retards or even reverses atherogenesis. Finally, evidence from primary and secondary prevention trials has established the efficacy of interventions to lower cholesterol concentrations, both dietary and pharmacological, in reducing the incidence of coronary heart disease. As a consequence of these and other studies two recent consensus conferences concluded that a reduction in serum cholesterol concentrations, if applied on a population basis, would contribute appreciably to public health. Seeking to shift the population distribution of serum cholesterol concentrations, the study group of the
European Atherosclerosis Society recommended a reduction in intake of saturated fat and cholesterol for the general population.' Similarly, the Consensus Conference on Lowering Blood Cholesterol to Preven Heart Disease convened by the United States National Heart, Lung, and Blood Institute concluded that as a goal of national health policy "All Americans (except children younger than 2 years of age) should be advised to adopt a diet that reduces total dietary fat intake." In consequence, much effort is now directed internationally, under both state and private auspices, at lowering serum cholesterol concentrations in the population as a whole.

Although large primary prevention trials have established that lowering serum cholesterol concentrations by either dietary or pharmacologic intervention reduces incidence of coronary heart disease events (predominantly acute myocardial infarction), only one randomised trial found mortality from coronary heart disease to be lowered significantly after cholesterol reduction ${ }^{3}$; moreover, no study provided evidence that lowering cholesterol concentrations extends survival. The failure of intervention to affect total mortality in primary prevention trials is due in part to a trend in several studies toward higher rates of deaths from cancer and from accidents and suicide among groups receiving treatment to lower cholesterol concentrations..$^{4-6}$ Additionally, most primary prevention trials were designed to detect only overal differences in the major coronary heart disease events (that is, fatal and non-fatal events combined) between intervention and control groups; these studies may therefore have had insufficient statistical power to detect group differences in mortality associated with treatment to lower cholesterol concentrations. Severa such randomised trials have been completed and it is possible by aggregating results of all available studies to test the hypothesis that reducing cholesterol concentrations lowers both total and cause specific mortality. Accordingly, we examined the effects of lowering cholesterol concentrations in primary prevention trials on total mortality and on death attributable to coronary heart disease, cancer, and causes not related to illness (predominantly accidents, violence, and suicide), using meta-analytic techniques that combine results of multiple studies designed to test similar hypotheses.

\section{Methods}

SELECTION AND DESCRIPTION OF STUDIES

A study was included in our meta-analysis if it me four criteria. Firstly, it was a randomised clinical primary prevention trial of serum cholesterol reduction. Secondly, it included a treatment group that received instructions for a diet or was given drugs, or all these studies had intended to test the hypothesis both, to reduce cholesterol, and had a control group: 
that lowering cholesterol prevents coronary heart disease. Thirdly, it resulted in a lowering of serum cholesterol in the intervention group, relative to the control group. Fourthly, it reported both total mortality and cause specific mortality.

A primary prevention trial was defined as any investigation in which criteria for participants' eligibility did not include a history of coronary heart disease. Studies were located with the ancestry approach (locating previous studies cited in reference lists of studies already located), computer based literature searches, and interviews with established clinical investigators of the treatment of hypercholesterolaemia.

Six investigations were located that met the above criteria: the colestipol-Upjohn study, ${ }^{3}$ the Los Angeles Veterans Administration trial, ${ }^{4}$ the Lipid Research Clinics coronary primary prevention trial, ${ }^{5}$ the Helsinki heart study, ${ }^{6}$ the World Health Organisation trial, ${ }^{7}$ and the Minnesota coronary survey. ${ }^{8}$ Five other prevention trials were identified but excluded because they did not randomise patients $s^{9.11}$ or they included interventions targeted at multiple risk factors simultaneously (the multiple risk factor intervention trial ${ }^{12}$ and the Oslo Study Group trial ${ }^{13}$ : in multiple intervention trials, it is not possible to attribute differences in outcome between the intervention and control groups to the actions of any specific treatment.) No trials were excluded for having inadequately reported cause specific mortality data.

Table I describes the six trials included in this analysis. Four of these trials enrolled only male participants ${ }^{4.7}$ and two enrolled both men and women. ${ }^{38}$ To achieve maximally homogeneous groups for comparison only the data for men were included in our analysis; however, including mortality data for women from the one investigation for which such information is available ${ }^{\gamma}$ did not alter our results. Participants' mean ages were similar in five of the trials, ranging from 45 to 51 years, whereas the men enrolled in the Veterans Administration study had a mean age of 65 . Most participants were white. Mean serum cholesterol concentrations before treatment in the study populations ranged from 5.35 to $7.96 \mathrm{mmol} / \mathrm{l}$, and the prevalence of smoking ranged from $36 \%$ to $79 \%$ (two trials did not provide data on smoking state). Two trials excluded men with high blood pressure whereas the others allowed, or even selected for, mild hypertension. These six trials subsumed 24847 participants and approximately 119000 person years of follow up.

Each trial randomised participants to the intervention or control conditions with equal probability. Cholesterol reduction in the intervention groups was accomplished in two trials (table I) by dietary interventions aimed at reducing consumption of cholesterol and saturated fat and in the four other trials by pharmacological treatment, with each using a different drug.

Relative to corresponding control conditions, the treatments used in these six trials each successfully lowered the average cholesterol concentration of participants in the intervention group, with a mean reduction across all trials of about $10 \%$ (table II). Interestingly, the dietary studies produced larger relative reductions in cholesterol concentrations than did the four pharmacotherapy trials. It should be noted that in two of the four drug treatment trials (Lipid Research Clinics study and Helsinki heart study) both the intervention and control groups were given dietary recommendations. In these studies efficacy of the drug interventions, as reported in table II, reflects cholesterol reduction achieved above and beyond any changes attained by dietary modification.

The dependent measures for analysis were the total number of deaths in the intervention and control groups and the observed mortality from coronary heart disease, cancer, and causes not related to illness. Mortality not related to illness subsumes deaths attributable to suicide, accidents, and homicide. (These causes of violent or "unnatural" death have been found to aggregate in a variety of populations and in epidemiologic studies of temporal mortality trends. ${ }^{14-17}$ Because there is also a significant positive association between violent behaviour and attempted suicide ${ }^{18}$ it has been hypothesised that a predisposition to self destructive or risk taking behaviour increases risk for both suicide and violent death. ${ }^{19}$ )

\section{DATA ANALYSIS}

For each trial, $2 \times 2$ contingency tables were constructed reflecting the number of participants who had died or were still alive at the end of treatment in both the intervention and control conditions, for the categories of total mortality and mortality related to coronary heart disease, cancer, and causes not related to illness.

The resulting $2 \times 2$ tables were combined according to the Mantel-Haenszel procedure ${ }^{20}$ as modified by

TABLE I-Description of randomised primary prevention trials

\begin{tabular}{|c|c|c|c|c|c|}
\hline & Subjects & Interventions & $\begin{array}{c}\text { No of } \\
\text { participants }\end{array}$ & Mean age & $\begin{array}{l}\text { Mean cholesterol } \\
\text { concentration before } \\
\text { treatment }(\mathrm{mmol} / \mathrm{l})\end{array}$ \\
\hline $\begin{array}{l}\text { Los Angeles Veterans } \\
\text { Administration study } \\
\text { (1968) }\end{array}$ & $\begin{array}{l}\text { Men in domicilary care, age }>55 \\
\text { diabetes, alcohol abuse, serious } \\
\text { illness excluded }\end{array}$ & $\begin{array}{l}\text { Cholesterol lowering diet } \\
v \\
\text { Conventional cafeteria diet }\end{array}$ & $\left.\begin{array}{l}424 \\
422\end{array}\right\}$ & 65 & 6.03 \\
\hline $\begin{array}{l}\text { Minnesota coronary } \\
\text { survey }(1975)^{\star}\end{array}$ & $\begin{array}{l}\text { Adult residents of mental hospitals; no } \\
\text { illness restrictions, no cholesterol } \\
\text { concentration requirements }\end{array}$ & $\begin{array}{l}\text { Cholesterol lowering diet } \\
v \\
\text { Control diet }\end{array}$ & $\begin{array}{l}2197 \\
2196\end{array}$ & 47 & $5 \cdot 35$ \\
\hline $\begin{array}{l}\text { World Health } \\
\text { Organisation study } \\
\text { (1978) }\end{array}$ & $\begin{array}{l}\text { Men aged } 30-59 ; \text { cholesterol } \\
\text { concentration in top third of } \\
\text { participants screened; clinical } \\
\text { coronary heart disease, diabetes, } \\
\text { and hypertension excluded }\end{array}$ & $\begin{array}{l}\text { Clofibrate } 1.6 \mathrm{~g} / \text { day } \\
\text { Placebo }\end{array}$ & $\left.\begin{array}{l}5331 \\
5296\end{array}\right\}$ & 46. & $6 \cdot 41$ \\
\hline $\begin{array}{l}\text { Colestipol-Upjohn study } \\
(1978)^{\star}\end{array}$ & $\begin{array}{l}\text { Adults; cholesterol concentration } \\
>6.5 \mathrm{mmol} / \mathrm{l} ; \text { no liver, kidney, } \\
\text { thyroid disease }\end{array}$ & $\begin{array}{l}\text { Colestipol } 15 \mathrm{~g} / \text { day } \\
\text { Placebo }\end{array}$ & $\begin{array}{l}548 \\
546\end{array}$ & 51 & $7 \cdot 96$ \\
\hline $\begin{array}{l}\text { Lipid Research Clinics } \\
\text { coronary primary } \\
\text { prevention trial (1984) }\end{array}$ & $\begin{array}{l}\text { Men aged } 35-59 \text {; low density lipoprotein } \\
\text { cholesterol concentration } \\
>4.5 \mathrm{mmol} / \mathrm{l} \text { and not responsive to } \\
\text { diet; clinical coronary heart disease, } \\
\text { diabetes, and hypertension excluded }\end{array}$ & $\begin{array}{l}\text { Cholestyramine } 24 \mathrm{~g} / \text { day and diet } \\
\text { recommendation } \\
v \\
\text { Placebo and diet recommendation }\end{array}$ & $\begin{array}{l}1906 \\
1900\end{array}$ & 48 & $7 \cdot 24$ \\
\hline $\begin{array}{l}\text { Helsinki heart study } \\
\text { (1987) }\end{array}$ & $\begin{array}{l}\text { Men aged } 40-55 ; \text { cholesterol } \\
\text { concentration }>5 \cdot 2 \mathrm{mmol} / 1 \text {; clinical } \\
\text { coronary heart disease and insulin } \\
\text { dependent diabetes excluded }\end{array}$ & $\begin{array}{c}\text { Gemfibrozil } 1200 \mathrm{~g} / \text { day and diet } \\
\text { recommendation } \\
v \\
\text { Placebo and diet recommendation }\end{array}$ & 2051 & 47 & $7 \cdot 47$ \\
\hline
\end{tabular}

^Only data for men included in analysis. 


\begin{tabular}{|c|c|c|c|c|c|c|c|c|c|c|}
\hline & \multirow{2}{*}{$\begin{array}{l}\text { Years of } \\
\text { follow up }\end{array}$} & \multirow{2}{*}{$\begin{array}{l}\text { Cholesterol reduction } \\
(\%)^{\star}\end{array}$} & \multicolumn{2}{|c|}{ Total mortality } & \multicolumn{2}{|c|}{$\begin{array}{l}\text { Mortality from coronary } \\
\text { heart disease }\end{array}$} & \multicolumn{2}{|c|}{$\begin{array}{l}\text { Mortality from cancer (during } \\
\text { extended follow up) }\end{array}$} & \multicolumn{2}{|c|}{$\begin{array}{l}\text { Mortality from causes not } \\
\text { related to illness } \dagger\end{array}$} \\
\hline & & & Intervention & Control & Intervention & Control & Intervention & Control & Intervention & Control \\
\hline \multicolumn{11}{|l|}{ Los Angeles Veterans } \\
\hline Administration study & 8 & $12 \cdot 7$ & 174 & 177 & 41 & 50 & $31(38)$ & $17(27)$ & $4 \ddagger$ & $0 \ddagger$ \\
\hline Minnesota coronary survey $\S$ & $1 \cdot 1$ & $13 \cdot 6$ & 158 & 153 & 39 & 34 & 16 & 12 & 21 & 14 \\
\hline \multicolumn{11}{|l|}{ World Health Organisation } \\
\hline study & $5 \cdot 3$ & $9 \cdot 0$ & 128 & 87 & 36 & 34 & $42(206)$ & $25(197)$ & 18 & 15 \\
\hline Colestipol-Upjohn study $\S$ & 1.9 & $9 \cdot 6$ & 17 & 27 & 9 & 22 & 2 & 2 & 2 & 0 \\
\hline \multicolumn{11}{|l|}{$\begin{array}{l}\text { Lipid Research Clinics } \\
\text { coronary primary }\end{array}$} \\
\hline prevention trial & $7 \cdot 4$ & $8 \cdot 5$ & 68 & 71 & $30 \|$ & $38 \|$ & 16 & 15 & 11 & 4 \\
\hline Helsinki heart study & 5 & $9 \cdot 6$ & 45 & 42 & 14 & 19 & 11 & 11 & 10 & 4 \\
\hline Total (\% of participants) & & & $590(4 \cdot 74)$ & $557(4 \cdot 50)$ & $169(1 \cdot 36)$ & $197(1.59)$ & $118(0.95)$ & $82(0.66)$ & $66(0.53)$ & $37(0 \cdot 30)$ \\
\hline
\end{tabular}

*Change in cholesterol concentration in intervention group during trial relative to control group.

†Accidents, violence, trauma, and suicides.

$\ddagger$ Data on deaths not related to illness available for years $6-8 ; 318$ intervention and 317 control subjects during that time.

\$Only data for men included in analysis.

|Classified as "definite" deaths from coronary heart disease.

Yusuf et al. ${ }^{21}$ The findings of each trial were first expressed as the difference between the observed $(\mathrm{O})$ and expected $(E)$ number of deaths in the intervention group $(\mathrm{O}-\mathrm{E})$, where $\mathrm{E}=\mathrm{nd} / \mathrm{N}$, with $\mathrm{n}$ equal to the number of subjects in the treatment group and d equal to the number of subjects who died among $\mathrm{N}$ total subjects. The variance of each finding was expressed as $\mathrm{V}=\mathrm{E}(1-\mathrm{n} / \mathrm{N})(\mathrm{N}-\mathrm{d}) /(\mathrm{N}-1) \cdot \chi^{2}$ Tests for heterogeneity of association failed to provide evidence that the relation between cholesterol reduction and either total or cause specific mortality was inconsistent across the individual studies. The collective findings of all trials for each mortality category were then calculated using the sum of the observed minus expected values $(\Sigma(\mathrm{O}-\mathrm{E})=\mathrm{GT})$, with variance equal to the sum of the individual variances (VT).

The combined estimate of the odds of death among treated subjects relative to the controls (and associated $95 \%$ confidence intervals) was expressed as exp $(\mathrm{GT} / \mathrm{VT} \pm 1 \cdot 96 / \sqrt{\mathrm{VT}})$. Finally, the hypothesis that an odds ratio differs significantly from 1.0 was tested by $\mathrm{Z}=\mathrm{GT} / \sqrt{\mathrm{VT}}$. The $\mathrm{p}$ value of the resulting $\mathrm{Z}$ reflects the probability of observing such data if the null hypothesis (that there was no association between treatment condition and mortality) is true.

In individual studies effect size for each category of mortality was calculated as the difference between the proportions of the participants in the intervention group and the control group who died. Effect size for the individual trials was weighted by the inverse of its estimated variance (which is a function of sample size). A mean effect size was then calculated across studies for total and cause specific mortality ${ }^{22}$ 23; for this analysis effect size was expressed as the difference in annual mortality per 100000 men receiving treatment to lower cholesterol. $\chi^{2}$ Tests of the heterogeneity of effect sizes showed no evidence of heterogeneity.

\section{Results}

Table II shows the mortality in the six trials in terms of total and cause specific mortality. Table III presents results of the statistical analyses relating to the overall odds ratios with associated $95 \%$ confidence limits. The

TABLE III-Overall effects of lowering cholesterol concentrations on total and cause specific mortalities

\begin{tabular}{lccc}
\hline & $\begin{array}{c}\text { Overall odds ratio }(95 \% \\
\text { confidence interval) }\end{array}$ & Z score & \multicolumn{1}{c}{ p Value } \\
\hline Total mortality & $1.07(0.94$ to 1.21$)$ & 0.98 & 0.33 (two tailed) \\
$\begin{array}{l}\text { Mortality from coronary heart } \\
\text { disease }\end{array}$ & $0.85(0.69$ to 1.05$)$ & -1.53 & 0.06 (one tailed) \\
Mortality from cancer & $1.43(1.08$ to 1.90$)$ & 2.53 & 0.01 (two tailed) \\
Mortality not related to illness & $1.76(1.19$ to 2.58$)$ & 2.85 & 0.004 (two tailed) \\
\hline
\end{tabular}

*Sign reflects direction of effect of intervention: positive values correspond with higher mortality in intervention group compared with the control group; negative values correspond with lower mortality in the intervention group. columns for total mortality in Table II show that neither dietary nor pharmacological interventions seem to improve survival; overall, total mortality was higher in the intervention groups than in the control groups. Total mortality did not differ significantly between these groups, and the confidence interval of the odds ratio overlapped $1 \cdot 0$.

In the World Health Organisation trial an unanticipated excess mortality occurred in the intervention group, and it has been hypothesised that this may result from hepatobiliary disease secondary to clofibrate. ${ }^{7}$ When this trial was excluded from the aggregate analysis there was still no difference between mortality in the treatment and control groups $(Z=-0.35 ; p=0.7)$. Therefore, the evidence from clinical trials of primary disease prevention shows that survival among adult men who underwent a lipid lowering treatment was not improved. In contrast, reducing serum cholesterol concentrations tended to lower mortality from coronary heart disease. There were fewer deaths from coronary heart disease in intervention groups than in the corresponding controls (169 $v 197$ deaths). As an a priori hypothesis this treatment effect was of borderline significance, over all trials, based on a one tailed test $(p=0.06)$. The odds ratio for death from coronary heart disease among intervention groups relative to that among control groups was 0.85 (95\% confidence interval 0.69 to 1.05 ). The associated effect size estimate based on the combined results of these six trials shows that about 70 lives a year are saved for every 100000 men of comparable characteristics receiving treatment to lower cholesterol.

Because interventions for cholesterol reduction tended to lower the mortality from coronary heart disease but did not lower mortality from all causes we next sought to determine if lipid lowering interventions led to increases in mortality from causes other than coronary heart disease. There were more deaths from cancer in the intervention condition than among the control groups, and the overall odds ratio was 1.43 (1.08 to 1.90). In light of the hypothesis that excess deaths from cancer in the World Health Organisation study may be related to use of clofibrate ${ }^{7}$ analyses were also conducted excluding this study. The $95 \%$ confidence interval of the resulting odds ratio $(0.90$ to 1.89$)$ overlapped $1 \cdot 0$, and the $\mathrm{Z}$ score was not significant $(1 \cdot 65 ; \mathrm{p}=0 \cdot 10)$. Therefore, excluding the World Health Organisation results removed the association between cholesterol reduction and mortality from cancer. Finally, deaths from cancer occurring after the end of the intervention were reported for the World Health Organisation $^{24}$ and Veterans Administration ${ }^{25}$ studies. When these data were used in our analysis the mortality from cancer in intervention and control 
conditions was comparable (odds ratio $1.09 \quad(0.92$ to 1.29)). Notably, removing the World Health Organisation study from the analyses of mortality from coronary heart disease did not alter the protection against death from heart disease afforded by cholesterol reduction (odds ratio $0 \cdot 81 ; p=0 \cdot 03$ ).

In regarding mortality not related to illness, the chance of dying from suicide or violence was nearly twice as high in the intervention groups as in the control conditions (odds ratio $1.76(1 \cdot 19$ to $2 \cdot 58)$ ). A higher proportion of mortality not related to illness in the intervention groups was found in every study, and the association between treatment to lower cholesterol concentration and deaths from such causes was highly significant $(Z=2 \cdot 85 ; p=0 \cdot 004)$. The related effect size for death from causes not related to illness approximates 50 excess deaths a year per 100000 treated patients.

Although all six trials were designed to test the same hypothesis (that lowering serum cholesterol concentration prevents coronary heart disease), treatment modalities varied among trials. It is possible that the effects on mortality of reducing serum cholesterol concentration by drug treatment may differ from those associated with dietary modification. Accordingly, table IV presents the findings of analyses conducted on dietary and drug intervention trials separately. Because these supplementary analyses include fewer data the power to detect true treatment effects is correspondingly reduced. Nonetheless, neither treatment modality influenced total mortality whereas cholesterol reduction through pharmacological treatment, but not diet, lowered mortality from coronary heart disease significantly $(p=0 \cdot 04)$. Dietary modification but not drug treatment was associated with increased mortality from cancer $(p=0.04)$, an effect that was lost when the data from extended follow up were included $(\mathrm{Z}=1 \cdot 58, \mathrm{p}=0 \cdot 11)$. Comparison of effect size estimates, as recommended by Rosenthal, ${ }^{22}$ showed that neither of these apparent differences between dietary and pharmacological interventions were significant (mortality from coronary heart disease: $Z=0 \cdot 18$, $\mathrm{p}=0.89$; mortality from cancer: $\mathrm{Z}=-1 \cdot 12, \mathrm{p}=0 \cdot 26$ ). Finally, during cholesterol reduction the increased odds of death from causes not related to illness were comparable for trials of dietary and pharmacological treatments.

\section{Discussion}

Primary prevention trials have shown that reducing serum cholesterol concentrations with diets or drugs, or both, reduces the incidence of major coronary events (fatal and non-fatal events combined) in men; these interventions have not, however, been shown to alter mortality from all causes and, with one exception, the individual studies provide no evidence of improved

TABLE IV - Effects of lowering cholesterol concentrations by dietary and pharmacological interventions on total and cause specific mortalities

\begin{tabular}{|c|c|c|c|}
\hline & $\begin{array}{l}\text { Overall odds ratio ( } 95 \% \\
\text { confidence interval) }\end{array}$ & $Z$ score $^{\star}$ & $\mathrm{p}$ Value \\
\hline \multicolumn{4}{|c|}{ Dietary interventions studies $(n=2)$} \\
\hline Total mortality & $1.00(0.84$ to 1.20$)$ & 0.04 & 0.96 (two tailed) \\
\hline $\begin{array}{l}\text { Mortality from coronary heart } \\
\text { disease }\end{array}$ & & & \\
\hline disease & $0.95(0.69$ to 1.30$)$ & $-0 \cdot 34$ & 0.60 (one tailed) \\
\hline Mortality from cancer & $1.62(1.03$ to 2.57$)$ & $2 \cdot 08$ & 0.04 (two tailed) \\
\hline Mortality not related to illness & $1.76(0.94$ to 3.30$)$ & $1 \cdot 77$ & 0.08 (two tailed) \\
\hline \multicolumn{4}{|c|}{ Drug intervention studies $(n=4)$} \\
\hline Total mortality & $1.13(0.95$ to 1.36$)$ & $1 \cdot 36$ & 0.17 (two tailed) \\
\hline $\begin{array}{l}\text { Mortality from coronary heart } \\
\text { disease }\end{array}$ & & & \\
\hline disease & $0.78(0.59$ to 1.03$)$ & $-1 \cdot 74$ & 0.04 (one tailed) \\
\hline Mortality from cancer & $1.33(0.93$ to 1.89$)$ & 1.59 & $0 \cdot 11$ (two tailed) \\
\hline Mortality not related to illness & $1.75(1.07$ to 2.86$)$ & $2 \cdot 23$ & 0.03 (two tailed) \\
\hline
\end{tabular}

* Sign reflects direction of effect of intervention on mortality relative to control group: negative values correspond with lower mortality in intervention group, positive values with higher mortality. mortality that can be attributed specifically to lowered rates of coronary heart disease.

Results of the present analysis indicate that cholesterol reduction as a primary disease prevention strategy tends to lower mortality from coronary heart disease. Over all trials this effect approached significance only when a one tailed test was used. When drug intervention trials were considered alone, however, the reduction in coronary mortality related to treatment was significant $(\mathrm{p}=0 \cdot 04)$.

The observed $15 \%$ reduction in deaths from coronary heart disease is clinically important, yet the estimate of 70 deaths from heart disease prevented annually for every 100000 people treated is modest when compared with the numbers of people treated without demonstrable benefit in terms of mortality. That few lives were saved might have been due to the fact that mean cholesterol concentration was reduced in the intervention groups by only $10 \%$ compared with that in control subjects, as well as to the rather young age (45-51) of the cohorts enrolled in most of these studies and their associated low base rate of deaths from coronary heart disease. In addition, the mean duration of treatment was only 4.8 years. Hence a greater benefit in terms of mortality from coronary heart disease might be observed when treatment is more protracted or more efficacious. (Regarding treatment duration, however, in the four studies of at least five years' duration the overall odds ratio of mortality from coronary heart disease in treated men versus the control group remained $0 \cdot 85$.)

The failure of cholesterol reduction to reduce total mortality in several primary prevention trials has been commented on previously in enumerative reviews of these studies ${ }^{2627}$ and has prompted debate regarding the probable benefits of cholesterol reduction as a national health objective..$^{28-30}$ Our analysis shows that the six randomised trials, when considered in aggregate, failed to show a decrease in all cause mortality despite nearly 120000 person years of observation under treatment and control conditions. It has been suggested that mortality from cancer might be increased with cholesterol reduction, based on epidemiological evidence of an inverse association between serum cholesterol concentrations and incidence of cancer. ${ }^{3132}$ Our anlaysis indicates, however, that the increased incidence of cancer sometimes observed after cholesterol reduction in large clinical trials may be attributable to the carcinogenic properties of certain drugs and does not persist with extended follow up. This lack of a robust association between reduction of serum cholesterol concentration and cancer is corroborated by earlier reviews ${ }^{32} 33$ and suggests that the epidemiological association between low serum cholesterol concentrations and cancer may not represent a causal relation. Data on individual types of cancer were not generally provided in the reviewed trials, and until these are available the potential associations between cholesterol reduction and specific types of cancer cannot be studied.

Several investigators have noted somewhat higher rates of deaths not related to illness among patients treated to lower cholesterol, ${ }^{4-6}$ though this relation is not significant in any individual investigation. When analysed collectively, however, the six randomised trials showed that this association between cholesterol reduction and higher mortality not related to illness was highly significant and occurred with both dietary and pharmacological interventions. Though seemingly disparate entities, suicide and accidental or violent death have been linked epidemiologically, ${ }^{14-17}$ and it has been postulated that people dying from causes not related to illness may share common dispositional, behavioural, or neurochemical characteristics. ${ }^{19435}$ In the control conditions of the six studies analysed here 
the aggregate rate of mortality not related to illness compared favourably with that in population data. In 1980 the American national average mortality from motor vehicle accidents, homicides, and suicides among white men aged 45 to 54 was $62 / 100000^{36}$; the mortality not related to illness in the control groups of the primary prevention trials examined here is $64 / 100000$. In contrast, the rate of death from these causes was $107 / 100000$ among the intervention groups, suggesting that suicide and accidental or violent death may be unusually common in the treatment groups. Finally, although most secondary intervention trials of cholesterol reduction do not give data on deaths not related to illness, the largest such trial (the coronary drug project) reported $30 \%$ more deaths from accidents, suicides, and homicides in men receiving niacin than in those receiving placebo. ${ }^{3}$

The complementarity of the effects of cholesterol reduction on mortality from coronary heart disease and causes not related to illness is striking: compared with control subjects, treated groups had 28 fewer deaths per 100000 from coronary heart disease and 29 excess deaths from suicides, homicides, and accidents. This increased mortality from causes not related to illness was observed in both dietary and drug studies and could not be attributed to the disproportionate influence of any one study. Recalculating the odds ratio and $\mathrm{Z}$ score with serial deletion of each trial individually did not alter the principal result.

The observed reduction in mortality from coronary heart disease is obviously a predicted outcome as cholesterol reduction is proposed as rational preventive treatment for coronary artery disease, but there is no readily plausible explanation for the increased rate of suicide and accidental or violent death. A competing risks model would propose that preventing a common disease, such as coronary heart disease, may increase the likelihood of other causes of death ${ }^{38}$; but a near doubling of mortality in a single category of causes of death-especially of one with a low base rate in the population-is inconsistent with this hypothesis. Another possibility is that people who alter lifelong behaviour patterns (that is, modify their dietary habits) have changes in mood or behaviour sufficient to increase the risk for suicide, or they experience alterations in cognitive functioning (for example, attentional processes) in a manner that predisposes to accidental death. No systematic data are available to evaluate this hypothesis; moreover, this hypothesis is made less likely by the fact that the effects of lipid lowering on mortality not related to illness were noted in trials including pharmacological interventions as well as in those based on dietary modification alone.

A final possibility that must be considered is that this unanticipated finding reflects a direct relation between reduction of serum cholesterol concentration and increased suicide and accidental or violent death. There is some experimental evidence that modifying the fat in the diet has both neurochemical and behavioural consequences. In laboratory rats these include altered fluidity and cholesterol content of cell membranes within the central nervous system and effects on maze learning, pain threshold, and physical activity. ${ }^{39-42}$ Monkeys fed a diet low in saturated fat and cholesterol (modelled on American Heart Association recommendations) were significantly more aggressive than control animals consuming a diet high in fat and cholesterol. ${ }^{43}$

In human beings experimental investigations of the influences of serum lipid concentrations on either neurochemistry or behaviour are entirely lacking. A recent epidemiological study of cause specific mortality failed to show a consistent association between serum cholesterol concentration and accidental or violent death. ${ }^{4}$ Several clinical studies have, however, reported low serum cholesterol concentrations among criminals,${ }^{45}$ people with diganoses of violent or aggressive conduct disorders, ${ }^{1647}$ homicidal offenders with histories of violence and suicide attempts related to alcohol,,$^{48}$ and people with poorly internalised social norms and low self control. ${ }^{49}$ These data suggest associations between serum cholesterol concentration, neuronal function, and behavioural predispositions; the significantly higher mortality from accidental or violent death and suicide among people undergoing treatment to lower cholesterol concentrations warrants further investigation.

Whatever the explanation for the increased mortality not related to illness, these observations suggest that interventions to lower cholesterol concentrations do not have a robust favourable effect on overall survival, at least for men typical of these subject groups. To the extent that these findings may generalise across age and sex they also justify a more cautious approach to population based interventions for control of lipid concentrations. The protection provided against coronary heart disease through cholesterol reduction may be greatest in patients with the highest serum cholesterol concentrations before treatment (as was noted in the World Health Organisation study). If so, promotion of long term survival might be best achieved by targeting intervention efforts primarily at those people who are at particularly high risk for death from coronary heart disease: those with exceptionally high serum cholesterol concentrations, history of coronary disease, or several risk factors in addition to hypercholesterolaemia.

Preparation of this manuscript was supported in part by HL 40962 and HL 07560, United States National Institutes of Health.

1 Study Group of the European Atherosclerosis Society. Strategies for the prevention of coronary heart disease: a policy statement of the Europea Atherosclerosis Society. Eur Heart 7 1987;8:77-88.

2 Consensus conference. Lowering blood cholesterol to prevent heart disease. IAMA 1985;253:2080-6.

3 Dorr AE, Gundersen K, Schneider JC, Spencer TW, Martin WB. Colestipol hydrochloride in hypercholesterolaemic patients-effect on serum cholesterol and mortality. F Chronic Dis 1978;31:5-14.

4 Dayton S, Pearce ML, Hashmoto S, Dixon WJ, Tomiyasu U. A controlle clinical trial of a diet high in unsaturated fat in preventing complications clinical trial of a diet high in unsaturated fat in preven

5 Lipid Research Clinics Program. The Lipid Research Clinics coronary primary prevention trial results. $\mathscr{f} A M A$ 1984;251:351-74.

6 Frick $\mathrm{MH}$, Elo O, Haapa K, et al. Helsinki heart study: primary-prevention trial with gemfibrozil in middle-aged men with dyslipidemia. $N$ Engl f Med 1987;317:1237-45

7 Committee of Principal Investigators. A co-operative trial in the primary prevention of ischaemic heart disease using clofibrate. Br Heart $\mathrm{f} 1978$ 40:1069-118.

8 Frantz ID, Dawson EA, Ashman PL, et al. Test of effect of lipid lowering by diet on cardiovascular risk. Arteriosclerosis 1989;9:129-35.

9 Rinzler SH. Primary prevention of coronary heart disease by diet. Bull NY Acad Med 1968:44:936-48.

10 Turpeinen O, Karvonen MJ, Pekkarinen M, Miettinen M, Elosuo R, Paavilainen E. Dietary prevention of coronary heart disease: the Finnish mental hospital study. Int $\mathcal{\text { P E pidemiol 1979;8:99-118. }}$.

11 Krasno LR, Kidera GJ. Clofibrate in coronary heart disease: effect on morbidity and mortality. FAMA 1972;219:845-51.

12 Multiple Risk Factor Intervention Trial Research Group. Multiple risk factor intervention trial. FAMA 1982;248:1465-75.

13 Hjermann I, Holme I, VelveByre K, Leren P. Effect of diet and smokin intervention on the incidence of coronary heart disease. Lancet 1981;i:1301 10.

14 Holinger PC, Klemen EH. Violent deaths in the United States, 1990-1975 relationships between suicide, homicide and accidental deaths. Soc Sci Med 1982;16:1929-38

15 Porterfield AL. Traffic fatalities, suicide, and homicide. American Sociological Review 1960;25:897-901.

$16 \mathrm{Klebba} \mathrm{AJ}$. Comparison of trends for suicide and homicide in the United States, 1900-1976. In: Hays JR, Roberts TK, Solway KS, eds. Violence and the violent individual. New York: SP Medical and Scientific Books, the violent indin $1979: 127-48$.

17 Kivela SL. Relationship between suicide, homicide and accidental death among the aged in Finland in 1951-1979. Acta Psychiatr Scand 1982;72:15560 .

18 Virkkunen M, De Jong J, Bartko J, Linnoila M. Psychobiological concomitant of history of suicide attempts among violent offenders and impulsive fire setters. Arch Gen Psychiatry 1989;46:604-6.

19 Holinger PC. Violent deaths in the United States. New York: Guilford, 1987

20 Mantel N, Haenszel W. Statistical aspects of the analysis of data from retrospective studies of disease. FNCI 1959;22:719-48. 
21 Yusuf S, Peto R, Lewis J, Collins R, Sleight P. Beta blockade during and after myocardial infarction: an overview of the randomized trials. Prog Cardiovasc Dis 1985;27:335-71.

22 Rosenthal R. Meta-analytic procedures for social research. Beverly Hills: Sage, 1986.

23 DerSimonian R, Laird N. Meta-analysis in clinical trials. Controlled Clin Trials 1986;7:177-88.

24 Committee of Principal Investigators. World Health Organization cooperative trial on primary prevention of ischaemic heart disease with clofibrate to lower serum cholesterol: final mortality follow-up. Lancet 1984;ii:600-4

25 Pearce ML, Dayton S. Incidence of cancer in men on a diet high in polyunsaturated fat. Lancet 1971;i:464-7.

26 Oliver MF. Primary prevention of coronary heart disease: an appraisal of clinical trials of reducing raised plasma cholesterol. In: Yu PN, Goodwin JF, eds. Progress in cardiology. Vol 9. Philadelphia: Lea and Febiger, 1980:1-24.

27 Oliver MF. Reducing cholesterol does not reduce mortality. I Am Coll Cardiol 1988;12:814-7.

28 McCormick J, Skrabanek P. Coronary heart disease is not preventable by population interventions. Lancet 1988;ii:839-41.

Kola G. Heart panel's conclusions questioned. Science 1985;227:40-1.

30 Taylor WC, Pass TM, Shepard DS, Komaroff AL. Cholesterol reduction and life expectancy; a model incorporating multiple risk factors. Ann Int Med
ling 1987;106:605-14.

31 Isles CG, Hole DJ, Gillis CR, Hawthorne VM, Lever AF. Plasma cholesterol, coronary heart disease, and cancer in the Renfrew and Paisley survey. BrMed F 1989;298:920-4.

32 McMichael AJ, Jensen OM, Parkin DM, Zaridze DG. Dietary and endogenous cholesterol and human cancer. Epidemiol Rev 1984;6:192-216.

33 Ederer F, Leren P, Turpeinen O, Frantz ID. Cancer among men on cholesterol-lowering diets. Lancet 1971 ; ii: 203-6.

4 Roy A, Linnoila M. Suicidal behaviour, impulsiveness and serotonin. Acto Psychiatr Scand 1988;78:529-35.

35 Coccaro EF. Central serotonin and impulsive aggression. Br $\mathcal{F}$ Psychiatry 1989;155(suppl 8):52-62.

36 National Center for Health Statistics. Health United States, 1987. Washington, DC: US Government Printing Office, 1988. (DHHS publication No (PHS) DC: US Gov

37 Canner PL, Berge KG, Wenger NK, et al. Fifteen year mortality in coronary drug project patients: long-term benefit with niacin. $\mathcal{f}$ Am Coll Cardiol $1986 ; 8: 1245-55$
38 Birnbaum ZM. On the mathematics of competing risks. Washington, DC: US Government Printing Office, 1979. (DHEW publication No (PHS) 79. 1351.)

39 Kessler AR, Kessler B, Yehuda S. Changes in the cholesterol level, cholesterol-to-phospholipid mole ratio, and membrane microviscosity in rat brain induced by age and a plant oil mixture. Biochem Pharmacol 1985;34 $1120-1$.

40 Kessler AR, Kessler B, Yehuda S. In vivo modulation of brain cholesterol level and learning performance by a novel plant lipid: indications for interactions between hippocampal-cortical cholesterol and learning. Life Science 1986; 38:1185-92.

41 Coscina DV, Yehuda A, Dixon LM, Kish SJ, Leprohon-Greenwood CE. Learning is improved by a soybean oil diet in rats. Life Science 1986;38:1789.

42 Yehuda S, Leprohon-Greenwood CE, Dixon LM, Coscina DV. Effects of dietary fat on pain threshold, thermoregulation and motor activity in rats. Pharmacol Biochem Behav 1986;24:1775-7.

43 Kaplan JR, Manuck SB. The effects of fat and cholesterol on aggressive behaviour in monkeys [Abstract]. Psychosom Med 1990;52:226-7.

44 Pekkanen J, Nissinen A, Punsar S, Karvonen M. Serum cholesterol and risk of Pekkanen J, Nissinen A, Punsar S, Karvonen M. Serum cholesterol and risk of
accidental or violent death in a 25 -year follow-up. Arch Intern Med

45 Hatch FT, Reissell PK, Poon-King TMW, et al. A study of coronary heart disease in young men: characteristics and metabolic studies of patients and comparison with age-matched healthy controls. Circulation 1966;33:679. 703

46 Virkkunen M, Penttinen $H$. Serum cholesterol in aggressive conduct disorder: a preliminary study. Biol Psychiatry 1984;19:435-9.

47 Virkkunen $M$. Serum cholesterol in antisocial personality. Neuropsychobiolog 1979;5:27-30.

48 Virkkunen $M$. Serum cholesterol levels in homicidal offenders. Neuropsychobiology 1983;10:65-9.

49 Jenkins CD, Hames CG, Zyzanski SJ, et al. Psychological traits and serum lipids. I. Findings from the California psychological inventory. Psychosom Med 1969;31:115-28.

\title{
Treatment of osteoporosis with human parathyroid peptide and observations on effect of sodium fluoride
}

\author{
J Reeve, U M Davies, R Hesp, E McNally, D Katz
}

\section{Abstract \\ Objective-To evaluate the need for a randomised} study of treatment of spinal osteoporosis with human parathyroid peptide in the secondary prevention of crush fractures; to study the effect of human parathyroid hormone peptide 1-34 plus sex hormones on vertebral body cancellous bone; and, separately, to determine the effect of relatively low doses of sodium fluoride plus calcium on spinal bone mineral density.

Design-Open study of patients with primary or postmenopausal osteoporosis. All patients had serial bone densitometry of the spine by quantitative computed tomography and dual photon absorptiometry as well as serial densitometry of the radial midshaft (cortical) and radial distal (trabecular) bone by quantitative computed tomography. Changes in the spinal bone not forming the spongiosa of the vertebral bodies ("cortical" bone) were determined from the difference between the two axial measurements, after correction to the same units of measurement.

Setting-Northwick Park Hospital and Medical Research Council Clinical Research Centre.

Patients-24 Patients who fulfilled the conventional criteria for type 1 (vertebral) osteoporosis not secondary to recognised causes other than sex hormone deficiency and with at least one crush or wedge vertebral fracture and a spinal bone density (quantitative computed tomography) $<80 \mathrm{mg} / \mathrm{cm}^{3}$ or two or more fractures. Twelve patients received human parathyroid peptide and 12 sodium fluoride; they were not randomised.

Main outcome measures-Trends in axial and peripheral bone mass values determined by linear, time dependent regression analyses.
Results-The patients receiving the peptide showed a substantial increase in vertebral spongiosa (mean $25.6 \mathrm{mg} / \mathrm{cm}^{2}$ two years after the start of treatment). No significant changes were seen in spinal cortical or radial bone density. The patients receiving sodium fluoride showed roughly equal increases in cancellous and cortical bone over the same period (mean increase in vertebral spongiosa $16 \cdot 1 \mathrm{mg} / \mathrm{cm}^{3}$ ). No significant changes were seen in radial bone.

Conclusions-Treatment of postmenopausal women with human parathyroid peptide selectively increases spinal cancellous bone density by amounts that may prove useful in secondary prevention. Peptide treatment should now be tested in a randomised study in which the important end point is prevention of fractures as the usefulness of sodium fluoride in this context is doubtful.

\section{Introduction}

Three treatments have been shown substantially to increase iliac cancellous bone density in vertebral crush fracture osteoporosis: sodium fluoride (when accompanied by substantial calcium supplements ${ }^{1}$; human parathyroid peptide (fragment $1-34)^{2}$; and calcitonin alternating with oral phosphate, which is slightly less effective. ${ }^{3}$ Studies of spinal bone, however, have lagged because of the unavailability of reliable measurements of spinal bone mass. All three treatments also increased the duration of the formative phase of the iliac bone remodelling cycle so that the thickness of new bone laid down at sites of previous bone resorption was increased, ${ }^{4-6}$ and the pre-existing trabeculae became thicker. For mechanical reasons a doubling of the cross sectional area of the trabeculae may increase 